\title{
Influence of husband consent to family planning and spousal communication on the use of family planning among young mothers in peri-urban, Nigeria
}

\author{
Obasanjo Afolabi Bolarinwa
}

Department of Public Health, School of Nursing and Public Health Medicine, University of KwaZulu-Natal, South Africa.

Department of Demography \& Social Statistics, Obafemi Awolowo University, Nigeria

Olalekan Seun Olagunju

Department of Demography \& Social Statistics, Obafemi Awolowo University, Nigeria.

Akintayo Taiwo

Department of Demography \& Social Statistics, Obafemi Awolowo University, Nigeria.

We certify that this is an original article and has not been published somewhere else.

\begin{abstract}
Men are perceived as significant barriers to the uptake of contraception in some communities, and lack of spousal communication regarding contraception is evident in some studies conducted in South-West and Northern Nigeria. The objective is to identify and discuss how husband consent to family planning (FP) and spousal communication influence family planning use among peri-urban dwellers in Nigeria. The study was limited to the primary dataset collected among young mothers that resides in peri-urban between the age of 15-30 years in South West, Nigeria. The result showed that the use of family planning was high among the respondents whose husband give consent to the use of family planning, and respondents who had appropriate spousal communication. Similarly, respondents whose spouse asks questions or whose husband advises on communication are likely to use FP. On the other hand, respondents whose husband didn't give consent, respondents with inappropriate communication with the spouse, respondents whose spouses didn't give advice, and those whose spouses didn't ask questions are less likely to use FP.
\end{abstract}

Keywords: Husband Consent, Family Planning, Spousal Communication, Young Mothers, Peri-Urban

\section{Corresponding Author}

Obasanjo Afolabi Bolarinwa

Department of Public Health, School of Nursing and Public Health Medicine, University of KwaZulu-Natal, South Africa.

bolarinwaobasanjo@gmail.com +27838467184 


\section{Introduction}

A significant factor underlying high birth rates in sub-Saharan Africa is the lack of family planning, an estimated 35 million women in sub-Saharan Africa have an unmet need for family planning ${ }^{1,2}$. Meanwhile, Unsafe abortions account for about $14 \%$ of maternal deaths on the continent ${ }^{3}$ while roughly $51 \%$ of all maternal deaths involve African women aged from 15 to 29 years $^{4}$, with total fertility rates (TFR) of around five births per woman of reproductive age ${ }^{5}$. Consistent utilization of family planning (FP) methods has the full potential to decrease birth rate, maternal mortality rates ${ }^{6}$.

Impressive global gains have been made in recent decades in improving contraceptive prevalence rates and decreasing fertility rates. At the same time, increasing numbers of men and women in developing countries want to adopt family planning and exercise their right to freely decide the number and spacing of their children ${ }^{7}$.

Initially, women were the primary target for family planning. Still, there is growing recognition that reproductive health is a joint responsibility of men and women, several studies reported that men are vital persons in the reproductive decision-making process and their decisions have profound influences on women's health ${ }^{3,4,8}$, failure in involving men in family planning programs can hamper the contraceptive use of women even if they are educated and motivated because of opposition from their husbands 9 .

It has been reported that interventions to promote the involvement of men in family planning have yielded some positive results in other low-income countries ${ }^{10}$. Still, this concept is yet to be fully explored in Nigeria. Men are perceived as significant barriers to the uptake of contraception in some communities and lack of spousal communication regarding contraception being evident in studies conducted in South-West and Northern Nigeria $^{3,11}$.

Lack of access to reproductive health services among young women is associated with the increased risk of unplanned pregnancy; unsafe abortion; STIs, including HIV; and early school dropout due to pregnancy, youth constitute a crucial target in reproductive health Strategies, access to reproductive health services remains an issue for young women and men because of cultural, medical and financial barriers ${ }^{12}$. Previous researches have stressed the importance of helping young people in developing countries to be effective contraceptive users ${ }^{12-15}$.

A study in Ghana discovered that partners' consent to the use of family planning methods was very crucial to the success of any family planning intervention ${ }^{3}$, concurrenceagreement between partners developed through the process of couples openly discussing fertility preferences and desires increases the likelihood of contraceptive use ${ }^{16}$. 
The major driving force for health education is communication either at the interpersonal, group, cultural, or societal level; effective interpersonal communication skills are essential ingredients for a healthy social relationship within spousal relationship ${ }^{11}$.

Spousal communication encourages approval of family planning method such that $79 \%$ of woman who discussed with their partners use family planning method ${ }^{3}$, several studies in the past have shown that spousal communication can increase contraceptive uptake and continuation $^{8,11,17,18}$. Partner's agreement is a reliable predictive of positive on women's reproductive health outcomes ${ }^{19}$.

Spousal communication about fertility and family planning in Africa is quite low, and more exceptional communication may increase the accuracy of a spouse 's perception of family planning use ${ }^{20}$.

Studies conducted in two South-Western states, Nigeria, to examine the level of spousal communication and its impact on the use of contraceptives indicated that contraceptive use was high among couples who discussed and made joint decisions on contraception ${ }^{21}$.

Despite the government's and health workers' efforts at providing family planning services in Nigeria ${ }^{1}$, there are still underlying factors discouraging the use of these services, and the dominant factors are spousal's objection and lack of consent and communication ${ }^{10,14,22}$ among other resilient factors. Women should be free to choose or deny family planning services, including abortion or sterilization. Considering the low prevalence of contraceptives in Nigeria, there is need to promote the self-liberation ${ }^{23}$. Still, in African societies, men occupy crucial roles ${ }^{10}$, including taking reproductive health decisions ${ }^{8}$. Hence, it's imperative to examine the Influence of husband consent to family planning and spousal communication on the use of family planning among young mothers in peri-urban, Nigeria.

\section{Scope of the study}

This study was limited to the primary dataset collected among young mothers aged 15-30 years in a peri-urban of South-West, Nigeria. The young mothers are those who already had a child in the last year, and this study is expected to provide insight into how consent and communication among young partners influence family planning use.

\section{Main research question/Objectives}

The question of interest is to identify and discuss how spousal's consent and communication predict contraceptive use among young mothers in the peri-urban of South West, Nigeria.

\section{Significance of the research}


Conducting a study on how spousal consent and communication predict contraceptive use among young mothers in peri-urban of South West, Nigeria is particularly relevant for policymakers, since more information is needed about hidden factors that are significantly influencing the non/low use of family planning in Nigeria and knowing the factors could contribute to the development of programs that are particularly relevant to use of family planning in Nigeria.

\section{Methods}

\section{Sample size}

The study population comprised young mothers (within reproductive age 15 - 30 years) who already had a child in the last year. The study area was purposively chosen to capture contraceptive use among this group. The primary data collection was done in three senatorial districts of Osun state, Nigeria. 140 respondents were interviewed in each senatorial district to give 420 respondents in total.

\section{Research Instrument}

The study employed a cross-sectional method of data collection that is a quantitative method of data collection. Semi-structured questionnaires were used to collect information on socio-demographic characteristics, family planning use, communication, consent, and support among young mothers.

\section{Ethical considerations}

The researcher ensured that the informed consent of the respondent was sought by explaining the purpose of the study; anonymity was maintained by not including their names, and confidentiality was assured and kept as all information gotten were used strictly for this study. Before administering the questionnaire, a copy of the research protocol was submitted for a full review to the Research and Ethics committee of Institute of Public Health, Obafemi Awolowo University, Ile-Ife (IPH, OAU) and was approved with approval number HREC NO: IPHOAU/12/1446 and informed consent was obtained from each resident before the administration of the tool. 


\section{Data Analysis}

Table 1: Respondents and Respondents' Husband Socio-demographics characteristics

\begin{tabular}{|c|c|c|c|c|c|}
\hline Variable & $\begin{array}{c}\text { Frequency } \\
\mathrm{N}=420\end{array}$ & Percent & Variable & $\begin{array}{c}\text { Frequency } \\
\mathrm{N}=420 \\
\end{array}$ & Percent \\
\hline Respondent's age & & & Husband age & & \\
\hline Below 20 & 19 & 4.5 & $25-29$ & 96 & 22.9 \\
\hline $20-24$ & 99 & 23.6 & $30-34$ & 173 & 41.2 \\
\hline $25-29$ & 252 & 60.0 & $35-39$ & 110 & 26.2 \\
\hline $30+$ & 50 & 11.9 & $40+$ & 41 & 9.7 \\
\hline Mean age: 26 years, SD: 3.4 & & & Mean age: 33 years, SD: 5.4 & & \\
\hline $\begin{array}{l}\text { Respondent's level of } \\
\text { education }\end{array}$ & & & Husband level of education & & \\
\hline No formal education & 15 & 3.7 & No formal education & 2 & 0.5 \\
\hline Primary & 44 & 10.4 & Primary & 9 & 2.1 \\
\hline Secondary & 177 & 42.1 & Secondary & 138 & 32.8 \\
\hline Post-secondary & 184 & 43.8 & Post-secondary & 271 & 64.5 \\
\hline Respondent's religion & & & Husband religion & & \\
\hline Christianity & 279 & 66.4 & Christianity & 279 & 66.4 \\
\hline Islam & 139 & 33.1 & Islam & 141 & 33.6 \\
\hline Traditional & 2 & 0.5 & Traditional & 0 & 0.0 \\
\hline $\begin{array}{l}\text { Respondent's Occupation } \\
\text { status }\end{array}$ & & & Husband Occupation status & & \\
\hline Unemployed & 39 & 9.3 & Unemployed & 30 & 7.1 \\
\hline Employed & 381 & 90.7 & Employed & 390 & 92.9 \\
\hline \multicolumn{3}{|l|}{ Living arrangement } & & & \\
\hline Living with you & 338 & 80.5 & & & \\
\hline Living elsewhere & 82 & 19.5 & & & \\
\hline \multicolumn{3}{|l|}{ Family type } & & & \\
\hline Monogamous & 341 & 81.2 & & & \\
\hline Polygamous & 79 & 18.8 & & & \\
\hline \multicolumn{3}{|l|}{ Children ever born } & & & \\
\hline $1-2$ & 255 & 60.7 & & & \\
\hline $3+$ & 165 & 39.3 & & & \\
\hline Mean CEB: 2.2, SD: 1.0 & & & & & \\
\hline
\end{tabular}

Table 1 represents the respondents and respondents' husband socio-demographic characteristics. The table shows that more than half of the respondents were between age $25-29$ years $(60 \%)$ with an average age of 26 years. Respondent's level of education shows that the majority $(85.9 \%)$ attended secondary $(42.1 \%)$ and post-secondary $(43.8 \%)$. More than half of the respondents practice Christianity (66.4\%) as religion. The table also 
revealed that majority of the respondents $(90.7 \%)$ were employed, almost all were living with their husband/partner $(80.5 \%), 81.2 \%$ of the husband of respondents married just one wife and more than half had 1-2 children before the study with average children ever born of 2.2 children. While respondents' husband socio-demographics shows that the average age of the respondent's husband was 33 years, with almost half between the ages of 30-34 years. Level of education shows that more than half $(64.5 \%)$ have post-secondary education. Christianity was the dominant respondent's husband religion with $66.4 \%$, and almost all (92.9\%) were currently employed

Table 2: Spousal Communication, Husband consent to family planning and Use of FP

\begin{tabular}{|l|l|l|}
\hline Variable & Frequency N=420 & Percent \\
\hline \hline Communication on money matters & & \\
\hline Poor & 64 & 15.2 \\
\hline Good & 356 & 84.8 \\
\hline Communication on the number of children & & \\
\hline Poor & 114 & 27.1 \\
\hline Good & 306 & 72.9 \\
\hline Communication on use of Family Planning & & \\
\hline Poor & 92 & 21.9 \\
\hline Good & 328 & 78.1 \\
\hline Husband consent to family planning & & \\
\hline No & 96 & 22.9 \\
\hline Yes & 324 & 77.1 \\
\hline Use of family planning & & \\
\hline No & 77 & 18.3 \\
\hline Yes & 343 & 81.7 \\
\hline
\end{tabular}

Table 2 presents spousal communication, husband consent to family planning, and use of family planning. The table shows that majority of the respondents have good spousal communication with their husbands/partners in that $84.8 \%$ have good communication concerning money matters, $72.9 \%$ have good communication concerning the number of children, and $78.1 \%$ have good communication concerning communication around the use of family planning. The table also shows that $77.1 \%$ informed their husband/partner before using family planning, and the current use of family planning shows that $81.7 \%$ were using any method of family planning.

Table 3: Relationship between spousal communication, husband consent to FP and use of FP

\begin{tabular}{|l|l|l|l|}
\hline Variable & Use of Family planning \\
\hline \hline Communication on money matters & No & Yes & Total \\
\hline Poor & $43(67.2)$ & $21(32.8)$ & $\mathbf{6 4}$ \\
\hline Good & $34(9.6)$ & $322(90.4)$ & $\mathbf{3 5 6}$ \\
\hline Chi2: 120.36, P-value:0.000 & & & \\
\hline Communication on the number of children & & & \\
\hline Poor & $55(48.3)$ & $59(51.7)$ & $\mathbf{1 1 4}$ \\
\hline Good & $22(7.2)$ & $284(92.8)$ & $\mathbf{3 0 6}$ \\
\hline Chi2:93.51, P-value:0.000 & & & \\
\hline
\end{tabular}




\begin{tabular}{|l|l|l|l|}
\hline Communication on use of Family Planning & & & \\
\hline Poor & $54(58.7)$ & $38(41.3)$ & $\mathbf{9 2}$ \\
\hline Good & $23(7.0)$ & $305(93.0)$ & $\mathbf{3 2 8}$ \\
\hline Chi2:128.18, P-value:0.000 & & & \\
\hline Husband consent to family planning & & & \\
\hline No & $77(80.2)$ & $19(19.8)$ & $\mathbf{9 6}$ \\
\hline Yes & $0(0.0)$ & $324(100.0)$ & $\mathbf{3 2 4}$ \\
\hline Chi2:318.21, P-value:0.000 & & & \\
\hline
\end{tabular}

Table 3 presents the relationship between spousal communication, husband consent to family planning, and the use of family planning. The table shows that there is a significant relationship between spousal communication and use of family planning in that almost all the respondents that have good communication in terms of communication on money matters, communication on the number of children and communication on the use of family planning were using family planning $(90.4 \%, 902.8 \%$, and $93.0 \%$ respectively). The table also shows that husband consent to family planning was significantly related to the use of family planning in that all the respondents that seek consent from their husband were using family planning.

Table 4: Logistic regression of spousal communication on the use of family planning

\begin{tabular}{|l|l|l|l|}
\hline Variable & Odd ratio & P-value & Confidence interval \\
\hline \hline Communication on money matters: RC- Poor & $0.035^{*}$ & $1.0742-6.9110$ \\
\hline Good & 2.72 & \multicolumn{2}{l|}{} \\
\hline Communication on the number of children: RC- Poor & $1.0214-5.6220$ \\
\hline Good & $0.045^{*}$ & $2.5537-13.6013$ \\
\hline Communication on use of Family Planning: RC- Poor & $0.000^{*}$ & $\mathbf{0 . 2 3 8 0}-\mathbf{0 . 7 0 8 1}$ \\
\hline Good & 5.89 & $\mathbf{0 . 0 0 1}$ & \\
\hline constant & $\mathbf{0 . 4 1}$ &
\end{tabular}

Table 4 presents the logistic regression of spousal communication on the use of family planning. This was done to determine the Influence of spousal communication on the use of family planning. The results show that there is a significant relation relationship between spousal communication and the use of family planning in that respondents with good spousal communication in terms of communication on money matters, communication on the number of children, and communication on the use of family planning were more likely to use family planning.

Table 5: Logistic regression of husband's attitude during spousal communication on the use of FP

\begin{tabular}{|l|l|l|l|}
\hline Variable & Odd ratio & P-value & Confidence interval \\
\hline \hline Listen: RC- Yes & 2.48 & 0.093 & $0.8597-7.1703$ \\
\hline No & 0.24 & $0.003^{*}$ & $0.0971-0.6122$ \\
\hline Asks questions: RC- Yes & $0.000^{*}$ & $0.0407-0.1673$ \\
\hline No & 0.08 & 0.924 & $0.4305-2.5308$ \\
\hline Respond appropriately: RC- Yes & \multicolumn{5}{|l|}{} \\
\hline No & 1.04 & 0.924 \\
\hline Nhows interest: RC- Yes &
\end{tabular}




\begin{tabular}{|l|l|l|l|}
\hline Gives advice: RC- Yes & $0.010^{*}$ & $0.1673-0.7799$ \\
\hline No & 0.36 & \multicolumn{2}{l|}{} \\
\hline Expresses his feelings: RC- Yes & 1.97 & 0.086 & $0.9094-4.2602$ \\
\hline No & $\mathbf{1 9 . 2 9}$ & $\mathbf{0 . 0 0 0}$ & $\mathbf{1 0 . 6 4 4 8}-\mathbf{3 4 . 9 6 4 1}$ \\
\hline constant &
\end{tabular}

Table 5 presents the logistic regression of the respondent husbands' attitudes during spousal communication on the use of family planning. This was done to check the husband's attitude during spousal communication on the use of family planning. The results show that respondents with the husband that ask questions, respond appropriately, and advises on spousal communication were more likely to use family planning.

\section{Discussion}

This study examined the Influence of spousal communication and husbands' consent to family planning on the use of any methods of family planning among women who have already had one child before the commencement of the study. The result showed that the use of family planning was high among the respondents. This may be because of husbands' consent to and spousal communication concerning communication around the use of family planning ${ }^{24}$. Various studies have documented that spousal communication can increase family planning uptake and continuation, and partner's agreement is a strong predictive of positive on women's reproductive health outcomes ${ }^{6,17,24}$.

Spousal communication was significantly associated with the use of family planning in this study in that women with good spousal communication in terms of communication on money matters, communication on the number of children, and communication on the use of family planning were more likely to use family planning. This may be because effective spousal communication gave women the confidence to use contraceptives compared to women who had poor communication ${ }^{11}$.

The husband's attitude during spousal communication on the use of family planning was significantly associated with the use of family planning in this study in that women with husbands that ask questions, respond appropriately, and advises on communication were more likely to use family planning. This may be because men had good attitudes towards family planning practice $^{3}$.

\section{Conclusion}

The level of contraceptive use overall is low in Nigeria ${ }^{25}$. However, this study revealed a wide variation by spousal communication and husbands' consent to use of family planning in the use of any family planning method among young mothers aged 15-30years. Spousal communication was significantly associated with the use of family planning. Women with good spousal communication on the use of family planning were more likely to use family planning. Also, the husband's attitude during spousal communication on the use of family planning was significantly associated with the use of family planning in this study in that women with husbands that show good attitudes during spousal communication towards the use of contraceptive were more likely to use family planning. To further increase the use 
of contraceptives, spousal communication, and husband consent to the use of family planning should be taken into consideration. Efforts should be made to adopt policies and programs that encourage male involvement in decision-making processes regarding contraceptive use among their spouses.

\section{References}

1. Etukudo IW. Spousal approval, communication and contraceptive behaviour in rural Nigeria. African Journal of Midwifery and Women's Health. 2015;9(4):170176.

2. Weinreb A. Family planning programs for the 21st Century: rationale and Design. In: Taylor \& Francis; 2013.

3. Olaoye T, Oluwatosin A, Ogunsanmi O and Ayodele KO. Male spouses' support of family planning (FP) uptake by wives: the role of socio-biographical mediators. 2015.

4. Grant C and Bhardwaj M. Family Planning Communications. 2016.

5. Tilahun T, Coene G, Temmerman M and Degomme O. Couple based family planning education: changes in male involvement and contraceptive use among married couples in Jimma Zone, Ethiopia. BMC Public Health. 2015;15(1):682.

6. Ackerson $\mathrm{K}$ and Zielinski R. Factors influencing use of family planning in women living in crisis affected areas of Sub-Saharan Africa: A review of the literature. Midwifery. 2017;54:35-60.

7. PATH and United Nations Population Fund. Meeting the Need: Strengthening Family Planning Programs. Seattle: PATH/UNFPA; 2006.

8. Tilahun T, Coene G, Temmerman M and Degomme O. Spousal discordance on fertility preference and its effect on contraceptive practice among married couples in Jimma zone, Ethiopia. Reproductive health. 2014;11(1):27.

9. Adegbola $\mathrm{O}$ and Habeebu-Adeyemi FM. The influence of male partners on contraceptive usage in sub-Saharan Africa-Lagos experience. 2016.

10. Akaba G, Ketare N and Tile W. A community-based, mixed-methods study of the attitudes and behaviors of men regarding modern family planning in Nigeria. International Journal of Gynecology \& Obstetrics. 2016;135(1):86-90.

11. Fagbamigbe AF and Ojebuyi BR. Influence of spousal communication about family planning and HIV/AIDS-related issues on modern contraceptive use in Nigeria. Journal of Health Management. 2017;19(2):320-333.

12. Sidze EM, Lardoux S, Speizer IS, Faye CM, Mutua MM and Badji F. Young women access and use of contraception: the role of providers' restrictions in urban Senegal. International perspectives on sexual and reproductive health. 2014;40(4):176.

13. Phillips A, Fatusi AO, Akinyemi AI and Bello B. Quality of spousal relationship on procurement of abortion in Peri-Urban Nigeria. African journal of reproductive health. 2015;19(4):14-22. 
14. Sánchez-Páez DA and Ortega JA. Adolescent contraceptive use and its effects on fertility. Demographic Research. 2018;38:1359-1388.

15. Wirsiy FS and Yeika EV. Contraceptive Uptake among Adolescent Girls Attending Family Planning Units in Four Health Facilities in Cameroon. $J$ Womens Health Dev. 2019;2:048-057.

16. Yue K, O'Donnell C and Sparks PL. The effect of spousal communication on contraceptive use in Central Terai, Nepal. Patient education and counseling. 2010;81(3):402-408.

17. Murithi LK, Brault M, Schensul S, Singh R, Verma R and Jadhav K. Understanding couple communication and family planning in Zambia. 2016.

18. Shakya HB, Dasgupta A, Ghule M, Battala M, Saggurti N, Donta B, Nair S, Silverman J and Raj A. Spousal discordance on reports of contraceptive communication, contraceptive use, and ideal family size in rural India: a crosssectional study. BMC women's health. 2018;18(1):147.

19. Amos M. Contraceptive method choice and spousal communication: Examining the effect of family planning method using an instrumental variable approach. Sexual \& Reproductive Healthcare. 2019;22:100458.

20. Prata N, Bell S, Fraser A, Carvalho A, Neves I and Nieto-Andrade B. Partner support for family planning and modern contraceptive use in Luanda, Angola. African journal of reproductive health. 2017;21(2):35-48.

21. Ibrahim MS, Sabitu K, Bashir SS and Olorukooba AA. Spousal communication on family planning, pregnancy, and delivery care among men in rural Northern Nigeria. Sahel Medical Journal. 2018;21(2):88.

22. United Nations and Department of Economic and Social Affairs. Population Division (2019), World Population Prospects 2019: Highlights (ST/ESA/SER.A/423).

23. Bolarinwa OA and Olagunju OS. Knowledge and factors influencing long acting reversible contraceptive use among women of reproductive age in Nigeria. Gates Open Research. 2020;3(7):7.

24. Kurniati A, Chen C-M, Efendi F, Elizabeth Ku L-J and Berliana SM. Suami SIAGA: male engagement in maternal health in Indonesia. Health policy and planning. 2017;32(8):1203-1211.

25. Do M and Kurimoto N. Women's empowerment and choice of contraceptive methods in selected African countries. Int Perspect Sex Reprod Health. 2012;38(1):23-33. 